\title{
Oral hygiene status of Kuwaiti schoolchildren
}

\author{
S.A. Al-Mutawa, ${ }^{7}$ M. Shyama, ${ }^{7}$ Y. Al-Duwairi ${ }^{2}$ and P. Soparkar ${ }^{3}$
}

$$
\begin{aligned}
& \text { حالة صحة الفم لدى أطفال المدارس في الكويت }
\end{aligned}
$$

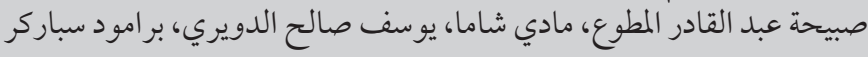

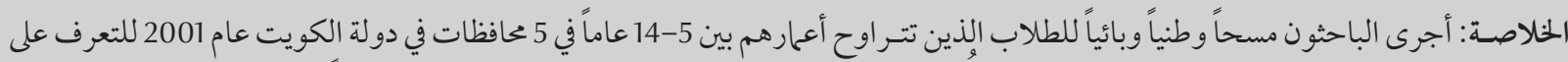

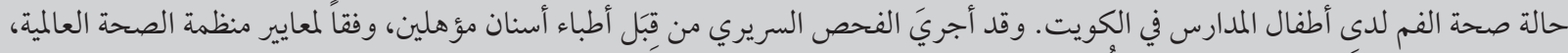

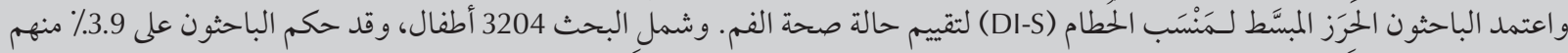

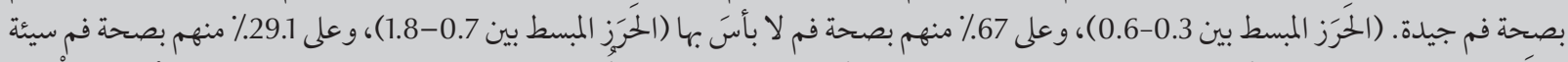

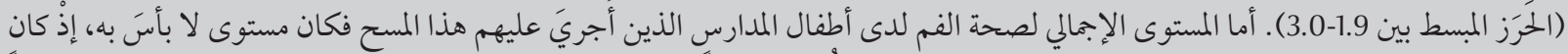

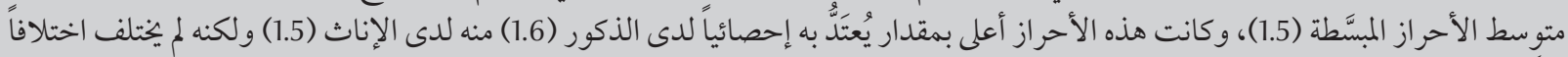

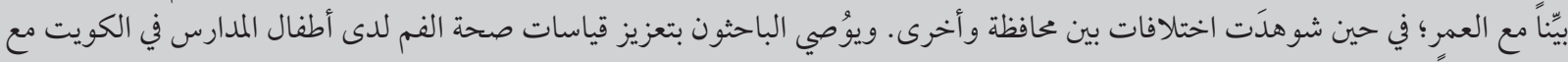
جعلها جزءاً من المقر رات الدراسية.

ABSTRACT A national epidemiological survey of children aged 5-14 years was conducted in all 5 governorates of Kuwait in 2001 to determine the oral hygiene status of Kuwaiti schoolchildren. Clinical examinations were carried out by calibrated dentists according to World Health Organization criteria. The debris index simplified (DI-S) score was used to assess oral hygiene status. Of the 3294 children, 3.9\% were judged to have good oral hygiene (DI-S score: 0.3-0.6), 67\% fair (score 0.7-1.8) and 29.1\% poor (score 1.9-3.0). The overall level of oral hygiene in the schoolchildren surveyed was fair (mean score 1.5). DI-S scores were significantly higher for boys than girls (mean score 1.6 versus 1.5) but DI-S did not vary much by age. There were variations in DI-S scores across different governorates. Oral hygiene measures need to be reinforced for the schoolchildren in Kuwait and should form part of the school curriculum.

\section{État d'hygiène bucco-dentaire des écoliers koweïtiens}

RÉSUMÉ Une enquête épidémiologique nationale a été conduite dans cinq gouvernorats du Koweït en 2001 pour déterminer l'état d’hygiène bucco-dentaire des écoliers koweïtiens âgés de 5 à 14 ans. Des examens cliniques ont été réalisés par des dentistes formés aux méthodes standardisées conformes aux critères de l'Organisation mondiale de la Santé. Le score de l'indice simplifié de débris (DI-S) a été utilisé pour évaluer leur état d'hygiène bucco-dentaire. Parmi les 3294 enfants, 3,9 \% avaient une bonne hygiène bucco-dentaire (score DI-S entre 0,3-0,6), 67 \% une hygiène acceptable (score DI-S 0,7-1,8) et 29,1 \% une mauvaise hygiène (score DI-S 1,9-3,0). Le niveau global d'hygiène bucco-dentaire chez les écoliers de l'enquête était acceptable (score moyen 1,5). Les scores DI-S étaient nettement plus élevés chez les garçons que chez les filles (score moyen 1,6 par rapport à 1,5) mais ne variaient que peu en fonction de l'âge. En revanche, ils variaient en fonction des différents gouvernorats. Les mesures d’hygiène bucco-dentaire doivent être renforcées chez les écoliers du Koweït et intégrées dans le programme scolaire.

'National School Oral Health Programme, Ministry of Health, Kuwait (Correspondence to M. Shyama: mshyama@yahoo.com).

${ }^{2}$ Dental Administration, Ministry of Health, Kuwait.

${ }^{3}$ Forsyth Institute, Boston, Massachusetts, United States of America.

Received: 01/04/2009; accepted: 18/10/2009 


\section{Introduction}

The primary etiological factor for gingivitis and periodontitis is bacterial plaque that forms on tooth surfaces adjacent to the gingival tissues [1]. Gingival diseases are widespread, affecting $80 \%$ of schoolchildren in some countries [2]. Periodontal disease has been considered an important global oral health burden and in many developing countries its prevalence is increasing, thereby constituting a growing public health problem [3]. Dental plaque is an associated factor for caries and it has been demonstrated that poor oral hygiene contributes to an increased risk of caries [4]. There is a high correlation between poor oral hygiene and the development of periodontal disease [5].

In Kuwait, the population is currently 3.3 million, of whom 1 million are native Kuwaitis; $40.5 \%$ of them are children under 15 years [6]. The national oral service of Kuwait was curative/ extraction-based prior to 1992 and only limited prevention programmes were available to schoolchildren before 1994. All the governorates of the country now have children's oral health programmes under the school oral health programme. The programme has expanded across the country, serving the oral health needs of about 300000 Kuwaiti schoolchildren. This is a comprehensive programme rendering oral health education, preventive and treatment services through centre-based, schoolbased and mobile clinics throughout the country. The programme's main goal is to improve the oral health status of the schoolchildren in Kuwait. To achieve optimum oral health for the schoolchildren, the programme's objective is to increase the proportion of schoolchildren receiving preventive oral health care every year to cover $90 \%$ of the children by the year 2010 .

Very little information is available concerning the oral hygiene of children on a national levelin Kuwait. The first national oral health survey was conducted among 5-16-year-old children in 1982 [7], the national health survey covered 5-14-year-olds in 1985 [8] and 4-, 6-, 12- and 15-year-olds in 1993 [9]. With the trend towards increasing prevalence and severity of dental caries [10], information concerning the oral hygiene status of young children would assist in the development of oral health policies, strategic plans, monitoring and surveillance systems of oral health in children in Kuwait.

The aim of this national survey was to obtain information on the oral hygiene status of schoolchildren attending the primary and intermediate schools in the 5 governorates of Kuwait.

\section{Methods}

\section{Sample}

The study population included Kuwaiti schoolchildren aged 5-14 years in the primary and intermediate grades in 5 governorates (Ahmadi, Farwaniya, Hawally, Jahra, Capital). A stratified, multistage, probability sample of $2.5 \%$ of the target population was drawn from each census region. A total of 3294 schoolchildren (1637 boys and 1657 girls) were clinically examined during 2001. Informed consent was signed by the parents/guardians of the children.

\section{Data collection}

The field staff consisted of 5 teams and a coordinator. Each team included an examining dentist, a recorder who was a dental hygienist and a dental assistant. Each examination team worked independently in the various schools. The examinations were carried out using portable equipment in the school dental clinic or in a school health room. Clinical examinations were carried out according to World Health Organization (WHO) methods [11]. Oral hygiene was assessed using the debris index simplified (DI-S) score, which describes the extent of soft deposits, and is one of the 2 components of the simplified oral hygiene index (OHI-S) developed by Green and Vermillion [12].

A mouth mirror and a WHO balltip probe were used for the examination. Oral debris was estimated by running the side of the probe along the teeth surfaces. The simplified DI-S evaluates 6 teeth surfaces: the labial surfaces of teeth $11,16,26,31$, and the lingual surfaces of 36 and 46 . Each tooth surface is divided horizontally into gingival, middle and incisal thirds. The scoring is: score 0: no debris or stain present; score 1: soft debris covering not more than one-third of the tooth surface; score 2: soft debris covering more than one-third but not more than two-thirds of the exposed surface; score 3: soft debris covering more than two-thirds of the exposed tooth surface. The DI-S score is the sum of the debris scores for all teeth, divided by the number of surfaces scored. For each child, the DI-S score was averaged across the 6 individual teeth in order to obtain a single score per child. To give clinical relevance to the index, oral cleanliness was defined as "good" if the DI-S score was between 0.3-0.6, "fair" between $0.7-1.8$ and "poor" between 1.9-3.0.

The examiners were trained to use the criteria for debris outlined in the OHI-S. Prior to the clinical examinations, the examiners were calibrated in the OHI-S method and were instructed in the measurement of oral hygiene by a consultant examiner from the Forsyth Institute (P.S.) according to WHO criteria [11]. The inter-examiner reliability of the oral hygiene assessment between the examiners was $80 \%$ and the intraexaminer reliability was $86 \%$.

\section{Data analysis}

Data were analysed using SPSS statistical software, version 14.0. Descriptive statistics including means and standard deviations (SD) were calculated for plaque indices. Differences in mean scores were tested using the Student $t$-test for independent samples. An independent-samples $t$-test was used to 
test the differences by sex. Chi-squared tests were used to test for differences in the frequencies of oral hygiene status by governorate, sex and age. One-way analysis of variance was used to test the differences in the mean oral hygiene index by governorate and age.

\section{Results}

Of the 3294 children examined, 3.9\% were judged to have good, $67 \%$ fair and $29.1 \%$ poor oral hygiene. The overall level of oral hygiene in the schoolchildren surveyed was fair (mean DI-S score 1.5). Significantly more of the girls (68.7\%) had fair oral hygiene than the boys $(65.3 \%)(P<0.001)$ and fewer had poor oral hygiene (26.7\% versus $31.6 \%$ ) (Table 1). The overall mean DI-S for females was 1.5 and for males $1.6(P<$ 0.001) (Table 2).

There was a significant difference in the oral hygiene status across the governorates. More than half (57.1\%) of the children had poor oral hygiene in Ahmadi compared to $11.0 \%$ in Hawally $(P<0.001)$ (Table 1). Also, the DI-S was highest in Ahmadi (1.9) and lowest in Hawally $(1.3)(P<0.001)$ (Table 2).

The cumulated plaque index for the index teeth was almost the same across the age groups and the mean DI-S did not vary significantly by age, ranging from 1.5 to 1.6 at different ages.

\begin{tabular}{|c|c|c|c|c|}
\hline \multirow[t]{2}{*}{ Variable } & \multirow{2}{*}{$\begin{array}{l}\text { No. of } \\
\text { children }\end{array}$} & \multicolumn{3}{|c|}{ Oral hygiene status (\% of children) } \\
\hline & & Good & Fair & Poor \\
\hline \multicolumn{5}{|l|}{ Sex } \\
\hline Male & 1637 & 3.1 & 65.3 & 31.6 \\
\hline Female & 1657 & 4.6 & 68.7 & 26.7 \\
\hline \multicolumn{5}{|l|}{ Governorate } \\
\hline Ahmadi & 582 & 4.9 & 38.0 & 57.1 \\
\hline Farwaniya & 573 & 2.8 & 81.0 & 16.2 \\
\hline Hawally & 863 & 5.1 & 83.9 & 11.0 \\
\hline Jahra & 757 & 4.4 & 68.3 & 27.3 \\
\hline Capital & 519 & 1.2 & 54.1 & 44.7 \\
\hline
\end{tabular}

Oral hygiene status: good = DI-S score 0.3-0.6; fair =DI-S score 0.7-1.8; poor $=$ DI-S score 1.9-3.0.

\section{Discussion}

This was a national dental epidemiological survey of the oral hygiene status of 5-14-year-old Kuwaiti schoolchildren. Knowledge of the oral hygiene status of target populations is important and the simplified oral hygiene index (OHI-S) was chosen for this study as it has been widely used to evaluate the level of oral cleanliness in epidemiological studies. The $\mathrm{OHI}$ was originally developed to include the measurement of 12 teeth surfaces [13]. Subsequently, it was reduced to 6 teeth surfaces $[12,14]$. This relatively simple assessment is fairly reproducible, easy to use since the criteria are objective and the examinations can be carried out quickly with a high level of reproducibility and with minimum training. Although the index has 2 components describing the soft deposits and the calcified deposits present, most clinicians used only one component of the OHI-S, the debris index simplified (DI-S); the simplified calculus index (CI-S) is no longer used to any great extent.

The overall oral hygiene status in the schoolchildren surveyed in the present study was fair. The mean DI-S index did not vary much by age. In the national survey conducted in 1982 by Glass the mean $\mathrm{OHI}$ scores increased with age [7]. The national health survey undertaken by Behbehani and Shah in 1985 revealed an increase in the prevalence of soft deposits with age [8]. In the postGulf-war national oral survey by Skougaard and Vigild in 1993 a majority of the children had poor oral hygiene [9]. In a study in the Ahmadi governorate,

\begin{tabular}{|c|c|c|c|c|c|c|c|c|}
\hline \multirow[t]{2}{*}{ Variable } & \multirow[t]{2}{*}{ No. of children } & \multicolumn{7}{|c|}{ Mean DI-S score for teeth: } \\
\hline & & 16 & 11 & 26 & 36 & 31 & 46 & Total \\
\hline \multicolumn{9}{|l|}{ Sex } \\
\hline Male & 1637 & 1.8 & 1.5 & 1.9 & 1.5 & 1.4 & 1.5 & 1.6 \\
\hline Female & 1657 & 1.7 & 1.4 & 1.8 & 1.4 & 1.3 & 1.4 & 1.5 \\
\hline \multicolumn{9}{|l|}{ Governorate } \\
\hline Ahmadi & 582 & 2.2 & 1.7 & 2.2 & 1.7 & 1.7 & 1.8 & 1.9 \\
\hline Farwaniya & 573 & 1.5 & 1.5 & 1.5 & 1.2 & 1.4 & 1.2 & 1.4 \\
\hline Hawally & 863 & 1.5 & 1.1 & 1.7 & 1.2 & 1.1 & 1.2 & 1.3 \\
\hline Jahra & 757 & 1.8 & 1.5 & 1.8 & 1.4 & 1.2 & 1.3 & 1.5 \\
\hline Capital & 519 & 2.0 & 1.6 & 2.1 & 1.7 & 1.4 & 1.7 & 1.7 \\
\hline
\end{tabular}


the plaque index increased with age and the children had poor oral hygiene [15]. In a study on disabled schoolchildren in Kuwait, $38 \%$ of the children had poor oral hygiene compared with $29.1 \%$ in this study [16]. Poor oral hygiene has been significantly associated with caries risk [17] and periodontal disease in disabled schoolchildren [16].

There were sex differences in oral hygiene status and the overall mean DI-S was higher in males than females in this study. This may be because females pay more attention to their personal hygiene and tend to practise better oral hygiene than males because of their greater social awareness and grooming habits [18].

There was a significant difference in the oral hygiene status between the governorates. The reason for regional differences is unclear and further research is needed.

Higher DI-S scores were noted in the molar index teeth compared with the incisor index teeth. This may be a reflection of the greater difficulty in cleaning the surfaces of the posterior teeth relative to the anterior teeth.

There have been rapid changes in lifestyle among Kuwaitis since the 1970s rise in oil prices and with increasing modernization and affluence. Toothbrushing is not common or routinely practised in schoolchildren in Kuwait. The proportion of children reported to be brushing at least once a day was $59 \%$ in the Kuwait health survey [8]. Although there is good evidence to recommend toothbrushing twice daily for control of plaque and gingivitis [19], only $54 \%$ of 12 -year-old children reported that they brushed their teeth at least twice a day in Kuwait [20]. There seems to be no progress in this oral health behaviour of schoolchildren in Kuwait. High consumption of sugar products is common among schoolchildren in Kuwait [20-22]. Routine dental visits are not a habit for the children in Kuwait. Studies showed that only about $36 \%$ of the children aged 5-14 years [8] and $42 \%$ of 12 -year-olds [20] had visited a dentist during the previous 12 months.

The school oral health programme in Kuwait is changing its general policy guidelines and is emphasizing oral health education and preventive care targeting schoolchildren. Oral health education is an important aspect of this programme and is presented by well- trained teams. All students get at least one oral health education lesson with a supervised toothbrushing exercise every school year. Oral health education sessions are organized for parents and pregnant mothers and dental health education programmes are conducted for schoolteachers. The programme is working with the media to promote oral health with messages promoting fluoride toothpaste and healthy food choices. Nevertheless, the results of the current study suggest that oral hygiene measures need to be reinforced for the schoolchildren in Kuwait and oral health education should form part of the school curriculum.

\section{Acknowledgements}

This survey was done by the School Oral Health Programme Kuwait-Forsyth. We thank L. Rose, Boston, for the statistical analysis of the data. We express our appreciation to all the staff of the oral health survey team for their cooperation and assistance. Our warmest thanks go to all the children, their parents and also to the school authorities for their wholehearted support.

\section{References}

1. Goldman HM. Periodontal disease. Part V: Manifestations of the disease having nonmicrobial origins. Compendium of Continuing Education in Dentistry, 1986, 7:316-318, 320, 322-326.

2. Oral health promotion through schools. WHO Information Series on School Health, Document 11. Geneva, World Health Organization, 2003.

3. Petersen PE et al. The global burden of oral diseases and risks to oral health. Bulletin of the World Health Organization, 2005, 83:661-669.

4. Ekstrand KR, Bruun G, Bruun M. Plaque and gingival status as indicators for caries progression on approximal surfaces. Caries Research, 1998, 32:41-45.

5. Page RC. Gingivitis. Journal of Clinical Periodontology, 1986, 13:345-355.

6. Public authority for civil information. Kuwait, Directory of Population and Labour Force, 2008.

7. Glass RL. Kuwait national dental health survey, part 1. The oral health of school children in 5-16 years of age in Kuwait 1982. Kuwait, Ministry of Health, 1982.

8. Behbehani JM, Shah NM. Oral health in Kuwait before the Gulf War. Medical Principles and Practice, 2002, 11(Suppl. 1):36-43.
9. Skougaard MR, Vigild M. Kuwait national oral health survey, oral health of 4, 6-, 12- and 15-year-old children in kindergartens and public schools in Kuwait. Kuwait, Ministry of Health, 1994.

10. Al-Mutawa SA et al. Dental caries experience of Kuwaiti schoolchildren. Community Dental Health, 2006, 23:31-36.

11. Oral health surveys: basic methods, 4th ed. Geneva, World Health Organization, 1997.

12. Greene JC, Vermillion JR. The simplified oral hygiene index. Journal of the American Dental Association, 1964, 68:7-13.

13. Greene JC, Vermillion JR. The oral hygiene index: a method for classifying oral hygiene status. Journal of the American Dental Association, 1960, 61:172-179.

14. Greene JC. The oral hygiene index-development and uses. Journal of Periodontology, 1967, 38 Suppl:625-637.

15. Skougaard MR et al. Oral health among Kuwaiti schoolchildren. The Danish Oral Health Program, Report on activities. Kuwait, Ministry of Health, 1988.

16. Shyama M et al. Oral hygiene and periodontal conditions in special needs children and young adults in Kuwait. Journal of Disability and Oral Health, 2000, 1(1):13-19. 
17. Shyama M et al. Dental caries experience of disabled children and young adults in Kuwait. Community Dental Health, 2001, 18:181-186

18. Dummer PM et al. The effect of social class on the prevalence of caries, plaque, gingivitis and pocketing in 11-12-year-old children in South Wales. Journal of Dentistry, 1987, 15:185-190.

19. Brothwell DJ, Jutai DK, Hawkins RJ. An update of mechanical oral hygiene practices: evidence-based recommendations for disease prevention. Journal of the Canadian Dental Association, 1998, 64:295-306.
20. Vigild M, Petersen PE, Hadi R. Oral health behaviour of 12year-old children in Kuwait. International Journal of Paediatric Dentistry, 1999, 9:23-29.

21. Petersen PE et al. Dental knowledge, attitudes and behavior among Kuwaiti mothers and school teachers. Journal of Pedodontics, 1990, 14:158-164.

22. Honkala S, Honkala E, Al-Sahli N. Consumption of sugar products and associated life- and school-satisfaction and selfesteem factors among schoolchildren in Kuwait. Acta Odontologica Scandinavica, 2006, 64:79-88.

\section{Oral health promotion}

Good oral health is essential for individuals to communicate effectively, to eat and enjoy a variety of foods, and is important for overall quality of life, self-esteem and social confidence. Oral diseases are highly prevalent in the Eastern Mediterranean Region (EMR) and their impact on both society and the individual is significant. Pain, discomfort, sleepless nights, limitation in eating function leading to poor nutrition, and time off school or work as a result of dental problems are all common effects of oral diseases. Industrialized countries spend 5\%-10\% of their annual national public health resources on dental care, but many countries in EMR allocate no, or only nominal, resources to the control of oral disease. In many developing economies of EMR, the only treatment for many in case of pain and problems with teeth is tooth extraction.

Regrettably, oral health has been and still is perceived as less important than and separate from general health by many, including health care providers, health policy-makers, and the general public. Oral health programmes have been developed in isolation from other health initiatives as against a common risk approach, which recognizes common health risks and their underlying social determinants. When applied, this approach is more efficient and effective in producing improvements in a range of chronic conditions, including oral health.

In order to address issues related to oral health, the WHO Regional Office is holding a meeting of oral health focal points from 31 May to 2 June 2011 in Isfahan, Islamic Republic of Iran. The barriers to the provision of equitable, adequate and accessible oral health care for all populations in the Region will be discussed, such as: lack of political support and legislation; limited numbers of dental care professionals; clustering of qualified dental care professionals in urban areas; cost of dental care; limited awareness of the importance of oral health; inequitable access to oral health care services, especially for vulnerable groups, such as women, children, indigenous people, the physically disabled and the elderly; cultural, social and gender barriers; and poor quality of health care.

An important aspect of the meeting will be to discuss a framework for an oral health policy in the Region, and countries will develop plans of action to operationalize the framework in their country 